\title{
Sol Gel Synthesis and Characterization of Zirconia Containing Hydrophobic Silica Nanoparticles
}

\author{
Tayseir M. Abd Ellateif ${ }^{1,2}$, and Saikat Mitra ${ }^{3}$ \\ ${ }^{1}$ Chemical Engineering Department, Universiti Teknologi PETRONAS, Tronoh-31750, Perak, Malaysia \\ ${ }^{2}$ Gas Processing Center, Qatar University-2713, Doha, Qatar \\ ${ }^{3}$ Governmental College of Energy \& Ceramic Technology, West Bengal University of Technology, 73, A. C, \\ Baverjee Lane, Kolkata-700010, India \\ Email: tayseir07@yahoo.com
}

\begin{abstract}
Hydrophobic mesoporous zirconia containing silica nanoparticles was synthesized via sol gel process. Silica sol was prepared and subsequently liquid modified with different proportions of zirconia. The effects of zirconia content on the silica textures and properties were studied. TGA results confirmed the development of hydrophobicity in zirconia containing silica nanoparticles. The synthesized nanoparticles were characterized by FTIR and XRF. The topography of silica particles changed as a function of zirconia content as evident from FESEM and TEM results. From XRD investigation, surface area measurement and pore size analysis it was observed that the synthesized silica was semi amorphous materials with very narrow pore diameter distribution as a function of zirconia content. From nitrogen physisorption studies mesoporous nature (type V) of the synthesized silica was noted. The synthesized pure silica possessed significant surface area while the zirconium content caused a reduction on the surface area of silica zirconium nanoparticles.
\end{abstract}

Keywords: Sol gel, Silica nanoparticle, surface modification, hydrophobic, zirconia

\section{Introduction}

Recently nanotechnology received considerable attention due to their potential application in many areas such as sensors, catalytic supports, solar cells, electronic, aerospace, defense, medical, and dental [1]. This involves design, synthesis, characterization, and application of materials and devices on the nanometer scale. The physical, chemical and biological properties at the nanoscale differ from the properties of individual atoms and molecules of bulk matter. Therefore, it provides opportunity to develop new classes of advanced materials which meet the demands from high-tech applications $[2,3]$.

Synthesis of metal oxides nanoparticles with specific sizes, shapes, and crystallinity has received considerable attention among the researchers. Silica nanoparticles is one of the materials of interest due to some of its excellent properties e.g., high specific surface area, particle size, light translucence and low cost of fabrication [4]. Silica can be produced with numerous topological forms like, single nanometer, nanotubes [5], nano-spheres [6], ultrathin films [7] and meso-porous silica [8]; all of which are holding great potentials in advanced applications such as photonics/optics, tailored drug-delivery [9] microelectronics and catalysis [10].

Silica nanoparticles can be synthesized using reverse micro-emulsion, flame synthesis and sol gel process. In the synthesis of silica nanoparticles using micro-emulsion, the nanoparticles can be grown inside the micro-cavities by adding the silicon alkoxides and catalyst into the medium containing reverse micelles [11]. In spite of the high cost and difficulties in removal of surfactants in the final products the reverse microemulsion method is applied for the coating of nanoparticles with different functional groups for various applications [12,13]. Silica nanoparticles can also be produced through high temperature flame decomposition of metal-organic precursors (chemical vapor condensation (CVC)) [14]. In CVC process, silica nanoparticles are produced by the reaction between silicon tetrachloride, $\mathrm{SiCl}_{4}$ with hydrogen and oxygen. The main drawback of this method is uncontrolled particle size, morphology, and phase composition[15]. Nevertheless, this is the well-known method that has been used to commercially produce silica nanoparticles in powder form. 
The sol gel process is used to produce silica, glass, and ceramic materials due to its ability to form pure and homogenous products at relatively mild conditions [16,17]. The process involves hydrolysis and condensation of metal alkoxides $\left(\mathrm{Si}(\mathrm{OR})_{4}\right)$ such as tetraethyl orthosilicate (TEOS, $\left.\mathrm{Si}\left(\mathrm{OC}_{2} \mathrm{H}_{5}\right)_{4}\right)$ or inorganic salts such as sodium silicate $\left(\mathrm{Na}_{2} \mathrm{SiO}_{3}\right)$ in the presence of acid (e.g., $\left.\mathrm{HCl}\right)$ or base $\left(\right.$ e.g., $\left.\mathrm{NH}_{3}\right)$. The general reactions of TEOS that leads to the formation of silica particles in the sol gel process can be written as the hydrolysis of TEOS molecules forms silanol groups. The condensation/polymerization between the silanol groups or between silanol groups and ethoxy groups creates siloxane bridges ( $\mathrm{Si}-\mathrm{O}-$ $\mathrm{Si})$ that form entire silica structure $[18,19]$.

Though, the most common way for synthesizing zirconia nanoparticles is based on the sol gel technique, the rapid reaction rate leads to agglomerates of amorphous particles [21]. Also, zirconia nanoparticles can be synthesized using other approaches such as mechano-chemical processing, modified emulsion precipitation etc. But most of these techniques result in a wide particle-size distribution [20]. Recently, some new routes have been developed for zirconia nanoparticles synthesis: a non-hydrolytic sol gel reaction route [21], a hydrolytic sol gel approach [22], a non-aqueous synthesis route [23] and lately mesoporous zirconia and sulfated zirconia nanoparticles were synthesized by using of triblock copolymer as template [24]. The main advantage of these new synthesis routes is the high yield of freestanding uniformly sized nanoparticles. On the other hand, they require tedious procedures, including the use of stabilizing surfactants and the resulting particle-crystallinity is poor. In addition, for some applications the achieved particle-size distribution of $4 \pm 2 \mathrm{~nm}$ is not sufficient [20].

$\mathrm{SiO}_{2}-\mathrm{MO}_{2}$ binary oxides are an interesting field of investigation for a wide spectrum of technological applications, comprising catalysis [25] and structural materials with enhanced physicochemical properties [26]. Such binary systems have been prepared by different routes, for instance, by chemical solution deposition [27] and by conventional sol gel synthesis [28].

Mixed oxides $\mathrm{SiO}_{2}-\mathrm{ZrO}_{2}$ have attracted great research attention in recent years because of their desired characteristics for many applications, like, alkali-durable glasses, catalyst supports and others [16]. Silica zirconia nanoparticles can be synthesized using different methods including postsynthesis which is a method usually used for the incorporation of zirconia onto mesoporous silica. However, postsynthesis grafting is more cumbersome and may destroy the uniform mesostructure and block the channels of the synthesized silica [25].

Kailasam et al. [27] synthesized mixed oxides by the calcination of silica-based inorganic-organic hybrid materials with embedded zirconium oxocluster $\mathrm{Zr}_{4} \mathrm{O}_{2}(\mathrm{OMc})$ are used as solid supports for subsequent alkyl chain functionalization (OMc 1/4 methacrylate). The hybrid materials were prepared starting from methacryloxypropyl trimethoxysilane (MAPTMS $\left.\left.1 / 4 \mathrm{CH}_{2}\right] \mathrm{C}\left(\mathrm{CH}_{3}\right) \mathrm{C}(\mathrm{O}) \mathrm{O}\left(\mathrm{CH}_{2}\right) \mathrm{Si}_{(}\left(\mathrm{OCH}_{3}\right)_{3}\right)$ which was copolymerized with the methacrylate-substituted zirconium oxocluster $\operatorname{Zr}_{4} \mathrm{O}_{2}(\mathrm{OMc})$. The hydrolysis and condensation reactions of the silane alkoxy groups form a silica network, whereas copolymerization of the methacrylate moieties in the oxocluster with the silane yields a covalent incorporation of the Zr-based building blocks into the silica hybrid backbone [27]. Combinations of silica with a large number of other oxides have also been reported, including silica-zirconia materials as synthesized by the sol gel method [29]. Among different preparation techniques of the oxide mixture, sol gel was often used for its controllability and the enhancement of physicochemical properties (high thermal and chemical stability or fracture toughness) of the resulted material [30].

The wettability of a solid surface is governed by both chemical composition and geometrical microstructure on the surface. A super-hydrophobic surface has attracted great interest for both fundamental researches and practical applications including biocompatibility, protective coatings, and stain-resistant finishes [31,32]. Generally, superhydrophobic surfaces are produced mainly in two ways. One is to create a rough structure on a hydrophobic surface [33-36], and the other is to modify a rough surface with low surface-energy materials $[37,38]$.

In this study, silica nanoparticles were synthesized using sol gel process, the chemical modification of silica surface to covert silica from hydrophilic to hydrophobic particles were conducted using different percentage of zirconia sol (liquid modification). The effects of different percentage of zirconia in the characteristics of the synthesized silica were investigated using different techniques. 


\section{Methodology}

\subsection{Materials}

Tetraethyl orthosilicate (TEOS) (98\% purity), zirconium (IV) ethoxide (99\% purity), ethylene diamine tetraacetic acid (EDTA) (99.5\% purity) from ACROS ORGANICS, ethanol (95\%) from HmbG chemicals, ammonia (25\% purity) and nitric acid (65\% purity) from R\&M chemicals. All chemicals were used as received.

\subsection{Synthesis of Silica Sol}

Silica sol was synthesized using $(0.5 \mathrm{M})$ of tetraethyl orthosilicate (TEOS). TEOS was used as the starting material, hydrolysis of the TEOS using (10M) of distilled water was carried out under base catalyzed condition using $(0.5 \mathrm{M})$ of ammonia. The hydrolysis ratio between water and TEOS was 2 .

\subsection{Synthesis of Zirconium Sol}

To synthesize zirconium sol two solutions were prepared. The first solution consists of EDTA and ammonia, with $\mathrm{NH}_{3}$ to EDTA ratio 4:1. The second one is a mixture of Zirconium butoxide and water with a ratio of 1:100. The two solutions were mixed together [39] and kept in oven at $60{ }^{\circ} \mathrm{C}$ for 24 hours to produce zirconium oxide as indicated in equations 1 and 2 below[40].

$$
\begin{gathered}
(\mathrm{RO})_{3}-\mathrm{Zr}-\mathrm{OR}+\mathrm{H}_{2} \mathrm{O} \leftrightarrow(\mathrm{RO})_{3}-\mathrm{Zr}-\mathrm{O}-\mathrm{H}+\mathrm{R}-\mathrm{OH} \\
(\mathrm{RO})_{3}-\mathrm{Zr}-\mathrm{O}-\mathrm{H}+\mathrm{R}-\mathrm{OH} \leftrightarrow(\mathrm{RO})_{3}-\mathrm{Zr}-\mathrm{O}-\mathrm{Zr}-(\mathrm{RO})_{3}+\mathrm{H}_{2} \mathrm{O}
\end{gathered}
$$

The synthesized zirconium sol which contains zirconium oxide was used to modify silica sol with different percentage 1, 3 and 5 vol\% to produce silica zirconium nanoparticles according to the following reaction (equation 3 ) and Figure 1.

$$
\mathrm{Si}-\mathrm{OH}+\mathrm{Zr}_{2} \mathrm{O}_{3} \leftrightarrow \equiv \mathrm{Si}-\mathrm{O}-\mathrm{Zr} \equiv+\mathrm{H}_{2} \mathrm{O}
$$

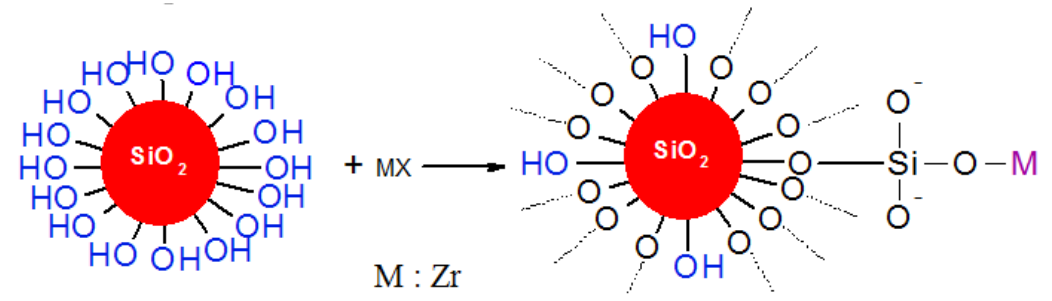

Figure 1. Silica surface modification.

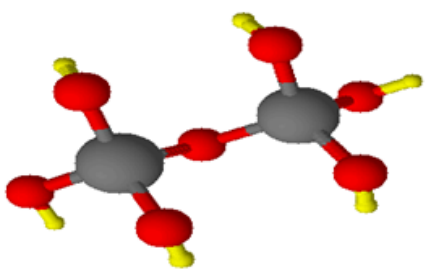

(a)

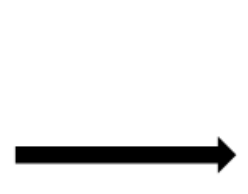

(b)

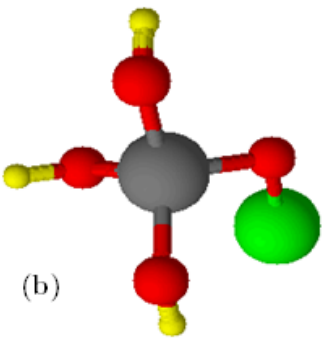

$\left(\mathrm{Si}(\bigcirc), \mathrm{O}(\bigcirc), \mathrm{H}(\bigcirc), \mathrm{Zr}()^{\circ}\right.$

Figure 2. Structure of (a) unmodified silica (b) modified silica nanoparticles. 


\subsection{Surface Modification of Silica Sol}

Silica sols thus synthesized were kept at room temperature $\left(25^{\circ} \mathrm{C}\right)$ for 20 minutes. Later they were modified with zirconia sol with different percentage $(1,3$ and 5$) \% \mathrm{vol} / \mathrm{vol}$ to produce silica zirconia nanoparticles. The predictable structure of the synthesized silica and silica zirconium was plotted using Chemsketch software as shown in Figure 2.

\subsection{Characterization}

The topography and the particle distribution of the synthesized silica nanoparticles were characterized using field emission scanning electron microscopy FESEM (Zeiss, SUPRA 55VP), and Transmission electron microscopy TEM (Zeiss, Libra 200). Fourier transforms infrared FTIR (Shimadzu FTIR-8400S), and X-ray fluorescence XRF (4kW S4 PIONEER) were used to confirm the synthesis and modification of silica. The powder X-ray diffraction pattern was measured using XRD (Bruker A \& S D8). BrunauerEmmett-Teller (BET) surface area and pore size (Micromeritics ASAP 2000) and thermo-gravimetric analysis TGA (Perkin-Elmer, Pyris V-3.81) were used to investigate the effect of zirconia percentage on silica nanoparticles surface area and its consequent thermal stability.

\section{$3 \quad$ Results and Discussion}

\subsection{Hydrophobicity of the Synthesized Silica}

The drying process of silica leads to the reaction between the $\mathrm{OH}$ groups at the surface of silica and ethanol. This phenomenon results in the formation of alkoxysilane groups that are responsible for the hydrophilic nature of the silica [41,42]. The synthesized pure and modified silica nanoparticles were tested for hydrophobicity by exposing them to moisture at $25^{\circ} \mathrm{C}$ and measuring the water adsorption by weight gain [43]. Figure 3 shows the weight gain of pure silica compared to silica modified with different percentage of zirconia. The low weight gain $\%$ of modified silica nanoparticles compared to the pure silica nanoparticles illustrates the hydrophobicity of modified silica nanoparticles. The synthesized pure silica over a period of 60 days depicts $8 \%$ weight gain. Whereas, the modified silica with $1 \%, 3 \%$ and $5 \%$ zirconium adsorbs moisture corresponding to $5 \%, 3 \%$ and $1 \%$ weight gain respectively over the entire period depending on zirconium percentage.

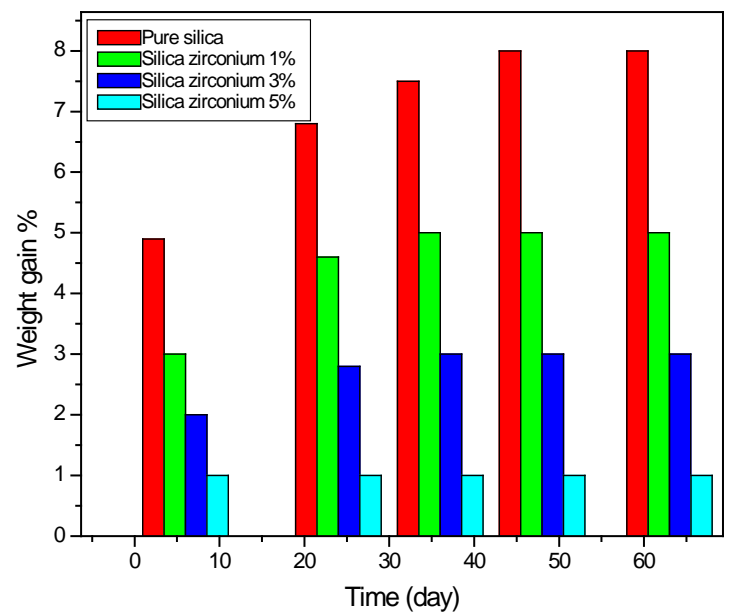

Figure 3. Hydrophobicity of the synthesized pure silica and silica zirconium nanoparticles.

\subsection{Thermal Stability of the Synthesized Silica Nanoparticles}

The thermal stability is a significant factor that determines the applicability of the materials for high 
temperature applications. Moreover, the physically adsorbed water and hydroxyl groups of nanoparticles are evaluated quantitatively by TGA. Figure 4 shows the thermo-gravimetric analysis of pure silica nanoparticles and silica modified with 1, 3 and 5\% zirconia. For pure silica nanoparticles the first $9 \%$ weight loss between 0 and $100^{\circ} \mathrm{C}$ is due to the loss of adsorbed water and moisture in the sample. The second $14 \%$ weight loss between $100^{\circ} \mathrm{C}$ and $400^{\circ} \mathrm{C}$ is due to the loss of strongly bonded (hydrogen bonded) water molecules. The final $16 \%$ loss between $400^{\circ} \mathrm{C}$ and $800^{\circ} \mathrm{C}$ is due to the condensation of silanol groups $(\mathrm{Si}-\mathrm{OH})$ to siloxane bonds $(\mathrm{Si}-\mathrm{O}-\mathrm{Si})$ with the removal of water. The Thermo-gravimetric analysis of the synthesized silica nanoparticles is identical to that in the literatures [44-47]. The thermal behavior of different compositions within the studied Si-O-Zr system exhibited TGA curve of the silica$1 \%$ zirconia sample with lower thermal stability while silica modified with $3 \%$ zirconia showed higher thermal stability. On the other hand, silica- 5\% zirconia showed highest thermal stability with low weight loss $\left(6 \%\right.$ and $9 \%$ ) at temperature ranges $0-100^{\circ} \mathrm{C}$ and $100-400^{\circ} \mathrm{C}$ respectively. The agreement between the TGA result and the hydrophobicity result (Figure 3) confirmed the modification of silica surface and indicated the conversion of silica from a hydrophilic to hydrophobic materials.

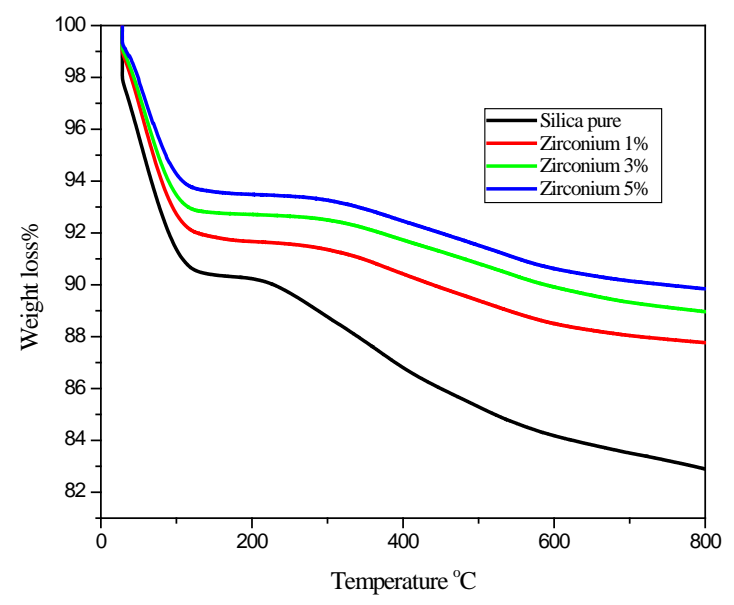

Figure 4. TGA thermal stability of the synthesized pure silica and silica zirconium nanoparticles.

\subsection{Morphology of the Synthesized Silica}

The morphology of the synthesized pure silica and modified silica with (1, 3 and 5\%) zirconia was studied using FESEM with $5000 \mathrm{KX}$ magnification as shown in Figure 5. The FESEM of pure silica showed that silica nanoparticles were fine particles with low packing density (Figure 5a). The particles were well dispersed and possessed a smooth surface with uniform distribution of particles. For silica modified with $1 \%$ zirconia (Figure 5b), the morphology appeared to be denser compared to that of pure silica. With the increase in the percentage of zirconia to $3 \%$ and $5 \%$ (Figure $5 \mathrm{c}$ and $5 \mathrm{~d}$ ), the zirconia spherical particles covered the surface and the morphology became more dense. For silica modified with $5 \%$ zirconia the topography showed agglomeration of particles.

\subsection{Particle Distribution of the Synthesized Silica Nanoparticles}

The TEM of pure silica nanoparticles illustrated spherical particles with particle size from $27 \mathrm{~nm}$ to $35 \mathrm{~nm}$ (Figure 5e). The electron micrograph of silica nanoparticles modified with different percentage of zirconia (Figure 5f, 5g, and 5h) illustrated different particle distribution of silica particles around zirconia particles. For silica modified with $1 \%$ zirconia, silica nanoparticles with particle size of $10 \mathrm{~nm}$ to $16 \mathrm{~nm}$ showed lower agglomeration around bigger spherical particles of zirconia with $64 \mathrm{~nm}$ to $69 \mathrm{~nm}$. With the increase in the percentage of zirconia to $3 \%$ and $5 \%$ small silica nanoparticles with size $15 \mathrm{~nm}$ to $16 \mathrm{~nm}$ aggregated and agglomerated around zirconia with particle size from $71 \mathrm{~nm}$ to $97 \mathrm{~nm}$. It is 
obvious from the TEM topography increasing zirconia content caused aggregation and agglomeration of silica and zirconia particles.

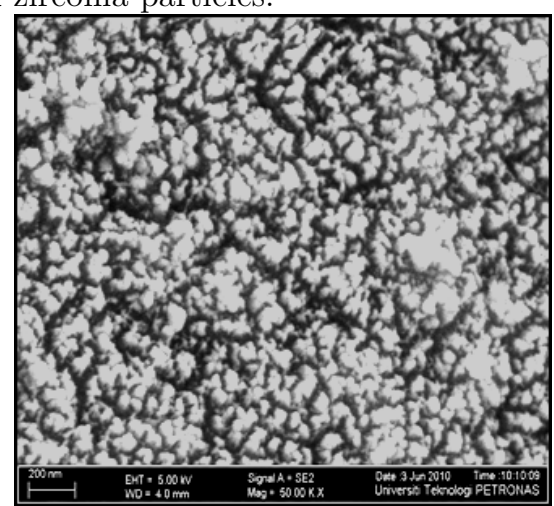

(a)

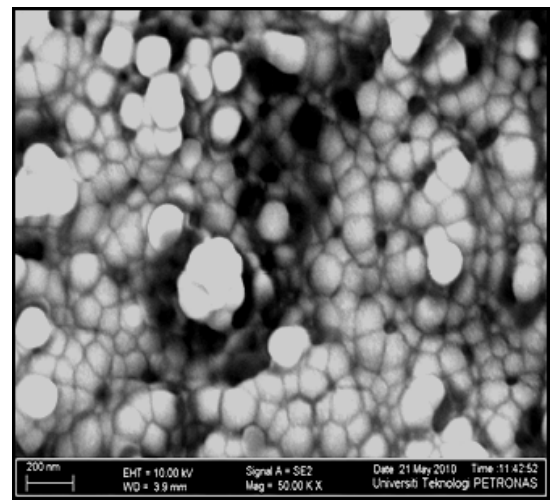

(b)

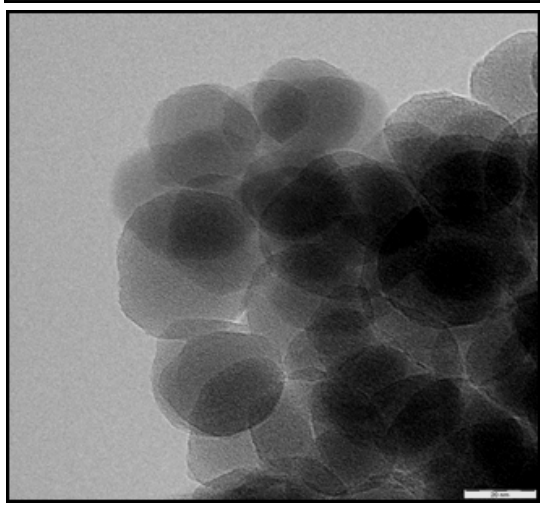

(e)

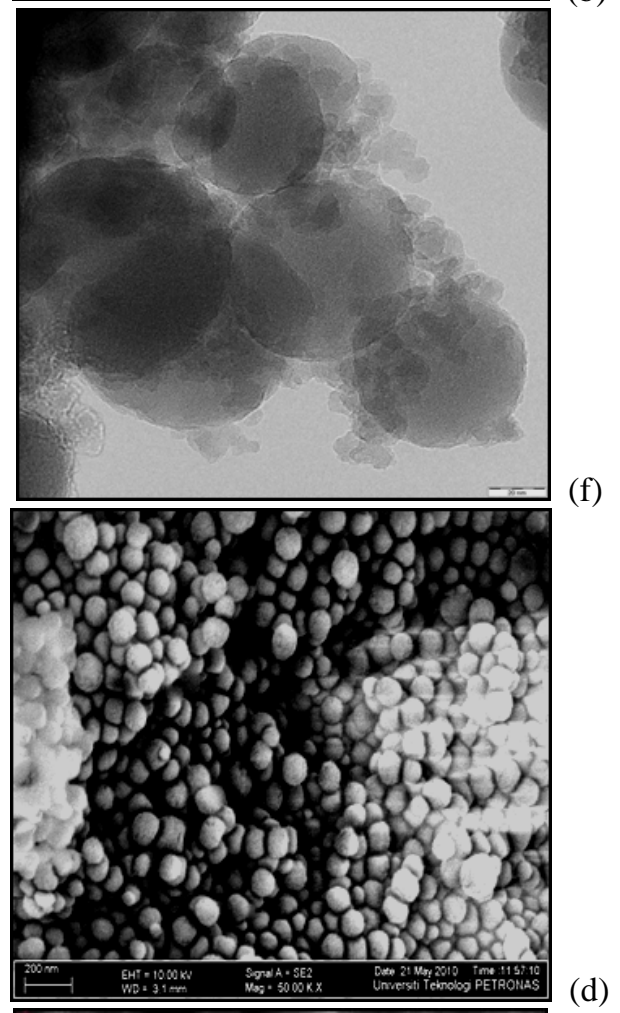

(c)

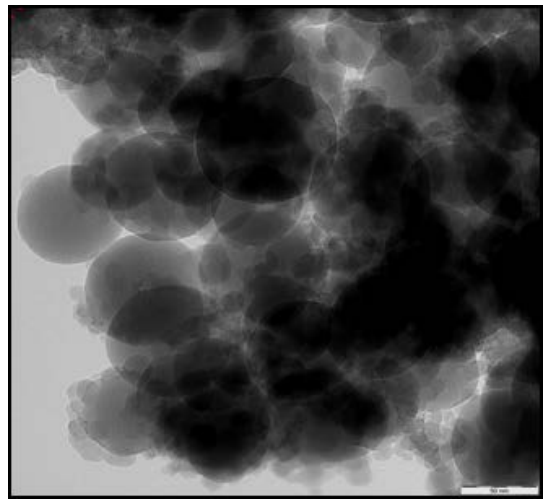

(d)

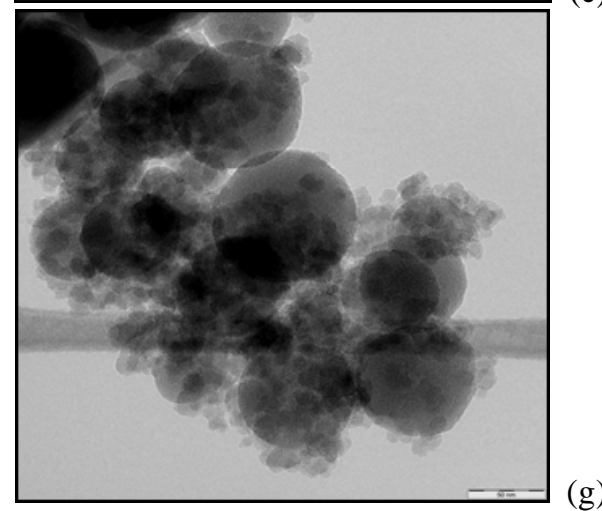

(g)

(h)

Figure 5. FESEM and TEM of the synthesized (a, e) pure silica (b, f) silica zirconium 1\% (c, g) silica zirconium $3 \%(\mathrm{~d}, \mathrm{~h})$ silica zirconium $5 \%$. 


\subsection{Chemical Structure of the Synthesized Silica Nanoparticles}

FTIR spectra of the synthesized pure silica nanoparticles displayed the surface Si-H stretching vibration at $800 \mathrm{~cm}^{-1}$. The adsorption peak presented at $900 \mathrm{~cm}^{-1}$ and $1631 \mathrm{~cm}^{-1}$ indicated the presence of Si-OH and $\mathrm{C}-\mathrm{H}$ respectively. The bands at $1090-1230 \mathrm{~cm}^{-1}$ confirmed the presence of silicon oxide ( $\mathrm{Si}-\mathrm{O}-\mathrm{Si}$ ), another band appearing at 3250-3700 $\mathrm{cm}^{-1}$ indicated the moisture at the surface of silica nanoparticles. The FTIR obtained for the synthesized silica nanoparticles agreed with the previous observation for silica materials [48-51]. The FTIR spectra of silica modified with 1\%, $3 \%$ and $5 \%$ zirconia sol have been presented in Figure 6 . The band occurring at $1635 \mathrm{~cm}^{-1}$ was due to the $\mathrm{C}-\mathrm{H}$ stretching vibration. The major peaks at $480-800 \mathrm{~cm}^{-1}$ and $1000-1250 \mathrm{~cm}^{-1}$ could be attributed to Zr-O and Si-O-Si bonds, respectively. The spectrum of modified silica zirconia in this figure showed bands at $971 \mathrm{~cm}^{-1}$ due to that the Si-O-Zr bond confirmed the replacement of Si-OH with Si-O-Zr. The FTIR obtained was in concurrence with the reported FTIR for silica and zirconia [52].

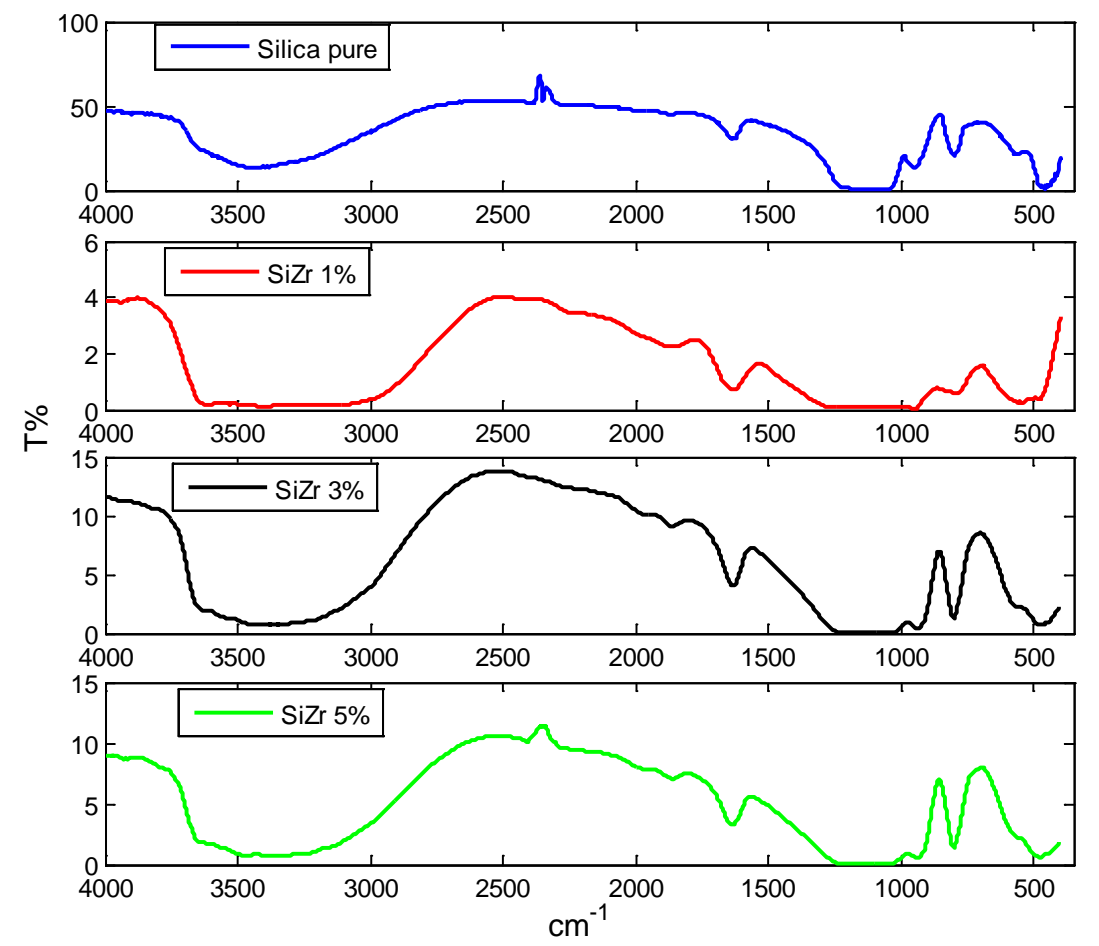

Figure 6. FTIR of the synthesized pure silica and silica zirconium nanoparticles.

\subsection{Composition of the Synthesized Silica Nanoparticles}

$\mathrm{XRF}$ was performed to determine the chemical compositions of the modified silica nanoparticles and to confirm that the metal oxides were anchored to the silica surface using liquid modification. The data given in Table 1 showed the composition of pure and modified silica nanoparticles. Silica and oxygen were present in major quantities while zirconia was present in traces amount as shown in Table 1. These results supported the FTIR investigation for pure silica and modified silica nanoparticles with different percentage of zirconia. The results exhibited that the intensity of zirconia increased with the increase in zirconia content from $1 \%$ to $5 \%$.

\subsection{Crystallinity of the Synthesized Silica Nanoparticles}

The XRD results illustrated silica nanoparticles prepared by the sol gel method was amorphous in nature (Figure 7.) In contrast the pure zirconia prepared by this method was found to be crystalline in 
nature with the peak positions corresponding to the presence of monoclinic phase [53]. For silica modified with $1 \%$ zirconia showed semi amorphous nature due to the regular distribution of zirconia at the surface of silica to form semi amorphous material. While with the increase in zirconia percentage to $3 \%$ and $5 \%$, these samples became semi amorphous. The reason for this discrepancy is that the presence of zirconia was barely enough to change the samples from amorphous to semi amorphous.

Table 1. XRF results of pure silica and silica zirconium nanoparticles

\begin{tabular}{ccccc}
\hline \multirow{2}{*}{ Sample } & \multirow{2}{*}{ Modifier $\%$} & \multicolumn{3}{c}{ Intensity $(\mathrm{KCps})$} \\
\cline { 3 - 5 } & & $\mathrm{Si}$ & $\mathrm{O}$ & $\mathrm{Zr}$ \\
\hline Pure silica & - & 45.66 & 53 & 0 \\
Silica zirconium & $1 \%$ & 46.21 & 53 & 0.0188 \\
& $3 \%$ & 46.22 & 53 & 0.0433 \\
& $5 \%$ & 45.97 & 53 & 0.07078 \\
\hline
\end{tabular}

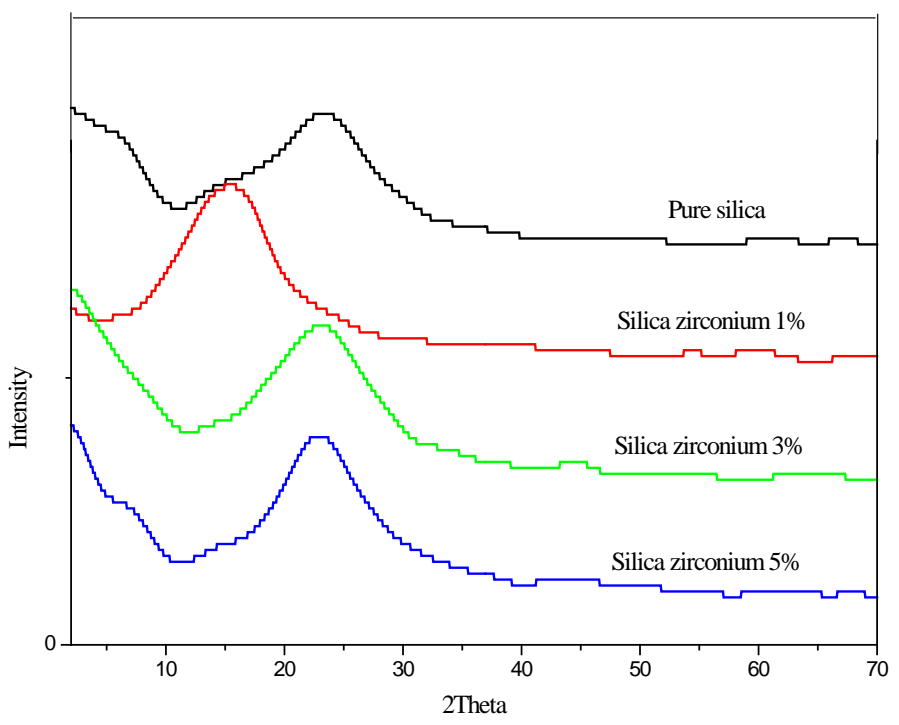

Figure 7. XRD of the synthesized pure silica and silica zirconium nanoparticles.

\subsection{Surface Area and Pore Size of the Synthesized Silica Nanoparticles}

The surface area and pore size analyzer using BET equation showed the surface area of pure silica nanoparticles was $303.69 \mathrm{~m}^{2} / \mathrm{g}$ (Table 2). For silica nanoparticles modified with 1,3 and $5 \%$ zirconia the surface area decreased with an increase in the amount of zirconia added to silica. The rough distribution of the zirconia particles for silica zirconium $1 \%$ as shown in TEM micrograph produces higher surface area compared to $3 \%$ and $5 \%$. The reduction in the surface area was due to the distribution of particles which lead to the reduction of silica zirconium nanoparticles pores volume (Figure 8b). Moreover, the increase in pores size from 4.8 to $6.8 \mathrm{~nm}$ with the increase in the percentage of zirconia yields decreasing on the surface area of silica zirconia $3 \%$ and $5 \%$. Figure 8 a illustrates the $\mathrm{N}_{2}$ adsorption-desorption isotherms plot for pure silica and silica-zirconia nanoparticles. The synthesized silica nanoparticles isotherms plots followed type (V) isotherm indicating all the synthesized silica and silica zirconia nanoparticles were mesoporous materials (pore size 2 to $50 \mathrm{~nm}$ ). These results demonstrated the agreement with the pore size calculated from BJH equation as shown in Table 2. 
Table 2. Surface area, pore volume and pore size of pure silica and silica zirconium nanoparticles.

\begin{tabular}{ccccc}
\hline Sample & Modifier $\%$ & $\begin{array}{c}\text { Pore volume } \\
\left(\mathrm{cm}^{3} / \mathrm{g}\right)\end{array}$ & $\begin{array}{c}\text { Pore size } \\
(\mathrm{nm})\end{array}$ & $\begin{array}{c}\text { BET } \\
\left(\mathrm{m}^{2} / \mathrm{g}\right)\end{array}$ \\
\hline Pure silica nanoparticles & - & 0.33 & 4.36 & 303.69 \\
Silica -zirconia & $1 \%$ & 0.23 & 4.80 & 192.73 \\
& $3 \%$ & 0.23 & 6.51 & 142.76 \\
& $5 \%$ & 0.24 & 6.81 & 142.63 \\
\hline
\end{tabular}
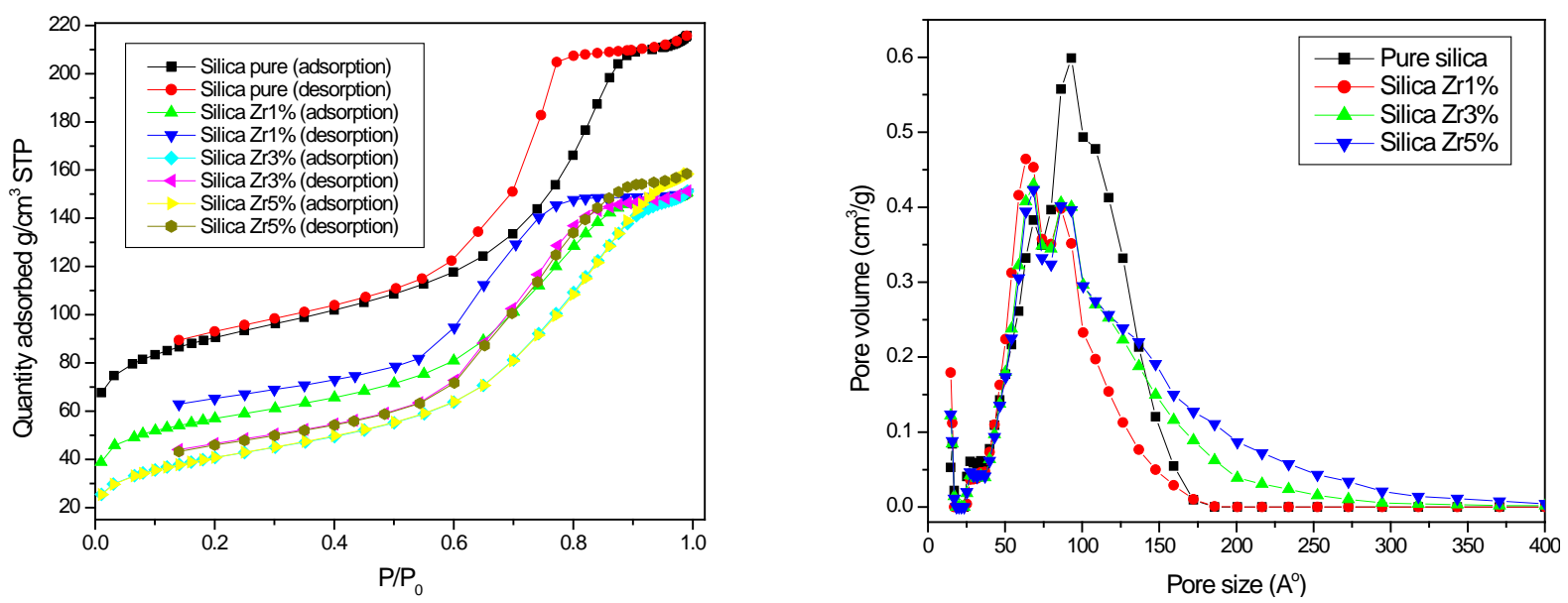

Figure 8. (a) $\mathrm{N}_{2}$ adsorption-desorption isotherms (b) pore size and pore volume distribution of the synthesized pure silica and silica zirconium nanoparticles.

\section{Conclusion}

Silica zirconia nanoparticles have been prepared by the sol gel method using liquid modification (silica sol modified with zirconia sol). Variations in the zirconia content produced silica with different texture and characteristics. TGA result indicated the highest thermal stability with lower weight loss of the synthesized silica zirconium up to $800^{\circ} \mathrm{C}$ compared to pure silica. The agreement between the hydrophobicity test and the obtained TGA results confirmed the hydrophobicity of the synthesized silica zirconia nanoparticles. FTIR and XRF were used to approve the synthesis and modification of silica. The characteristics result showed the influences of zirconia content on the texture, structure and morphology of the synthesized silica. Characterization techniques revealed that structural and textural properties were different for pure silica and silica zirconia depending on zirconium percentage. Mesoporous semi amorphous materials with very narrow pore diameter distribution were obtained using nitrogen adsorption-desorption isotherms and X-ray diffraction respectively. The surface area calculated using BET equation showed the reduction in the surface area for the silica zirconia nanoparticles.

\section{References}

1. G. Oskam, "Metal oxide nanoparticles: synthesis, characterization and application," Journal of Sol-Gel Science and Technology, vol. 37, pp. 161-164, 2006.

2. G. Kickelbick, "Concepts for the incorporation of inorganic building blocks into organic polymers on a nanoscale," Progress in Polymer Science, vol. 28, pp. 83-114, 2003.

3. Z. Wang and T. J. Pinnavaia, "Nanolayer Reinforcement of Elastomeric Polyurethane," Chem Mater, vol. 10, pp. 3769-3771, 1998. 
4. J. Tian, H. Zhang, M. Liu, F. Deng, H. Huang, Q. Wan, Z. Li, K. Wang, X. He, X. Zhang, and Y. Wei, "A bioinspired strategy for surface modification of silica nanoparticles," Applied Surface Science, vol. 357, Part B, pp. 1996-2003, 2015.

5. M. Adachi, "Formation processes of silica nanotubes and integrated ordered microstructures," Colloid and Polymer Science, vol. 281, pp. 370-385, 2003.

6. H.-P. Hentze, S. R. Raghavan, C. A. McKelvey, and E. W. Kaler, "Silica Hollow Spheres by Templating of Catanionic Vesicles," Langmuir, vol. 19, pp. 1069-1074, 2003.

7. D. A. Muller, T. Sorsch, S. Moccio, F. H. Baumann, K. Evans-Lutterodt, and G. Timp, "The electronic structure at the atomic scale of ultrathin gate oxides," Nature, vol. 399, pp. 758-761, 1999.

8. A. Monnier, F. Schüth, Q. Huo, D. Kumar, D. Margolese, R. S. Maxwell, G. D. Stucky, M. Krishnamurty, P. Petroff, A. Firouzi, M. Janicke, and B. F. Chmelka, "Cooperative formation of inorganic-organic interfaces in the synthesis of silicate mesostructures," Science, vol. 261, pp. 1299-1303, 1993.

9. N. Menon and D. T. Leong, "Cytotoxic Effects of Phosphonate-Functionalized Mesoporous Silica Nanoparticles," ACS Applied Materials \& Interfaces, vol. 8, pp. 2416-2422, 2016.

10. E. Flikkema and S. T. Bromley, "A new interatomic potential for nanoscale silica," Chemical Physics Letters, vol. 378, pp. 622-629, 2003.

11. T. T. Y. Tan, S. Liu, Y. Zhang, M. Y. Han, and S. T. Selvan, "5.14 - Microemulsion Preparative Methods (Overview) A2 - Andrews, David L," in Comprehensive Nanoscience and Technology, G. D. Scholes and G. P. Wiederrecht, Eds. Amsterdam: Academic Press, 2011, pp. 399-441.

12. S. Liu and M. Y. Han, "Silica-coated metal nanoparticles," Chem Asian J, vol. 5, pp. 36-45, 2010.

13. R. P. Bagwe, L. R. Hilliard, and W. Tan, "Surface Modification of Silica Nanoparticles to Reduce Aggregation and Nonspecific Binding," Langmuir, vol. 22, pp. 4357-4362, 2006.

14.G. A. Silva, "Introduction to nanotechnology and its applications to medicine," Surgical Neurology, vol. 61, pp. 216-220, 2004.

15. K. J. Klabunde and R. M. Richards, Nanoscale Materials in Chemistry: Second Edition, 2009.

16. J. Livage, C. Sanchez, M. Henry, and S. Doeuff, "The chemistry of the sol-gel process," Solid State Ionics, vol. 32, pp. 633-638, 1989.

17. R. G. R. Avendaño, J. A. d. l. Reyes, J. A. Montoya, and T. Viveros, "Effect of Synthesis Parameters on SolGel Silica Modified by Zirconia," Journal of Sol-Gel Science and Technology, vol. 33, pp. 133-138, 2005.

18. C. J. Brinker, "Hydrolysis and condensation of silicates: effects on structure," J. Non-Cryst. Solids, vol. 100, pp. 31-50, 1988.

19.L. L. Hench and J. K. West, "The sol-gel process," Chemical Reviews, vol. 90, pp. 33-72, 1990.

20. M. A. Ballem, J. M. Córdoba, and M. Odén, "Mesoporous silica templated zirconia nanoparticles," Journal of Nanoparticle Research, vol. 13, pp. 2743-2748, 2011.

21. J. Joo, T. Yu, Y. W. Kim, H. M. Park, F. Wu, J. Z. Zhang, and T. Hyeon, "Multigram Scale Synthesis and Characterization of Monodisperse Tetragonal Zirconia Nanocrystals," Journal of the American Chemical Society, vol. 125, pp. 6553-6557, 2003.

22. M. Mizuno, Y. Sasaki, S. Lee, and H. Katakura, "High-Yield Sol-Gel Synthesis of Well-Dispersed, Colorless ZrO2 Nanocrystals," Langmuir, vol. 22, pp. 7137-7140, 2006.

23. G. Garnweitner, L. M. Goldenberg, O. V. Sakhno, M. Antonietti, M. Niederberger, and J. Stumpe, "Large-Scale Synthesis of Organophilic Zirconia Nanoparticles and their Application in Organic-Inorganic Nanocomposites for Efficient Volume Holography," Small, vol. 3, pp. 1626-1632, 2007.

24. S. K. Das, M. K. Bhunia, A. K. Sinha, and A. Bhaumik, "Self-Assembled Mesoporous Zirconia and Sulfated Zirconia Nanoparticles Synthesized by Triblock Copolymer as Template," The Journal of Physical Chemistry C, vol. 113, pp. 8918-8923, 2009.

25. X. R. Chen, Y. H. Ju, and C. Y. Mou, "Direct Synthesis of Mesoporous Sulfated Silica-Zirconia Catalysts with High Catalytic Activity for Biodiesel via Esterification," The Journal of Physical Chemistry C, vol. 111, pp. 18731-18737, 2007.

26. U. A. Joshi, S. Yoon, S. Baik, and J. S. Lee, "Surfactant-Free Hydrothermal Synthesis of Highly Tetragonal Barium Titanate Nanowires: A Structural Investigation", The Journal of Physical Chemistry B, vol. 110, pp. 12249-12256, 2006. 
27. K. Kailasam, S. Mascotto, S. Gross, C. Maccato, and K. Muller, "Alkyl chain grafting on silica-zirconia mixed oxides: preparation and characterization," Journal of Materials Chemistry, vol. 20, pp. 2345-2355, 2010.

28. G. J. Owens, R. K. Singh, F. Foroutan, M. Alqaysi, C. M. Han, C. Mahapatra, H. W. Kim, and J. C. Knowles, "Sol-gel based materials for biomedical applications," Progress in Materials Science, vol. 77, pp. 1-79, 2016.

29. R. Gomez, F. Tzompantzi, T. Lopez, and O. Novaro, "ZrO2-SiO2 mixed oxides as supports for platinum catalysts," Reaction Kinetics and Catalysis Letters, vol. 53, pp. 245-251, 1994.

30. Y. Liu, K. Sun, X. Xu, and X. Wang, "HZSM-5 supported silica-zirconia and its application in one-step synthesis of methyl isobutyl ketone," Catalysis Communications, vol. 11, pp. 322-325, 2010.

31. L. Xue, J. Li, J. Fu, and Y. Han, "Super-hydrophobicity of silica nanoparticles modified with vinyl groups," Colloids and Surfaces A: Physicochemical and Engineering Aspects, vol. 338, pp. 15-19, 2009.

32. L. Xu and J. He, "Fabrication of Highly Transparent Superhydrophobic Coatings from Hollow Silica Nanoparticles," Langmuir, vol. 28, pp. 7512-7518, 2012.

33. Q. Fu, G. V. Rama Rao, S. B. Basame, D. J. Keller, K. Artyushkova, J. E. Fulghum, and G. P. López, "Reversible Control of Free Energy and Topography of Nanostructured Surfaces," Journal of the American Chemical Society, vol. 126, pp. 8904-8905, 2004.

34. J. T. Han, D. H. Lee, C. Y. Ryu, and K. Cho, "Fabrication of Superhydrophobic Surface from a Supramolecular Organosilane with Quadruple Hydrogen Bonding," Journal of the American Chemical Society, vol. 126, pp. 4796-4797, 2004.

35. B. Zhao, R. T. Haasch, and S. MacLaren, "Solvent-Induced Self-Assembly of Mixed Poly(methyl methacrylate)/ Polystyrene Brushes on Planar Silica Substrates: Molecular Weight Effect," Journal of the American Chemical Society, vol. 126, pp. 6124-6134, 2004.

36. X. Yang, L. Zhu, Y. Chen, B. Bao, J. Xu, and W. Zhou, "Controlled hydrophilic/hydrophobic property of silica films by manipulating the hydrolysis and condensation of tetraethoxysilane," Applied Surface Science, vol. 376, pp. 1-9, 2016.

37. B. He, N. A. Patankar, and J. Lee, "Multiple Equilibrium Droplet Shapes and Design Criterion for Rough Hydrophobic Surfaces," Langmuir, vol. 19, pp. 4999-5003, 2003.

38. A. Roig, E. Molins, E. Rodriguez, S. Martinez, M. Moreno-Manas, and A. Vallribera, "Superhydrophobic silica aerogels by fluorination at the gel stage," Chemical Communications, pp. 2316-2317, 2004.

39. M. L. Wang, B. L. Liu, C. C. Ren, and Z. W. Shih, "Preparation of the Precursor of the Zirconium Oxide in EDTA- Ammonia Solution by the Sol- Gel Method," Ind. Eng. Chem. Res, vol. 36, pp. 2149-2155, 1997.

40. T. M. López, D. Avnir, and M. A. Aegerter, Emerging fields in sol-gel science and technology: Springer Netherlands, 2003.

41. A. V. Rao and P. B. Wagh, "Preparation and characterization of hydrophobic silica aerogels," Materials chemistry and physics, vol. 53, pp. 13-18, 1998.

42. P. B. Wagh, A. V. Rao, and D. Haranath, "Influence of molar ratios of precursor, solvent and water on physical properties of citric acid catalyzed TEOS silica aerogels," Materials chemistry and physics, vol. 53, pp. 41-47, 1998.

43. Reynolds, J. G.Coronado, and L. W. P. R. Hrubesh, "Hydrophobic aerogels for oil-spill clean up-synthesis and characterization," J. Non-Cryst. Solids, vol. 292, pp. 127-137, 2001.

44. C. L. Chiang, R. C. Chang, and Y. C. Chiu, "Thermal stability and degradation kinetics of novel organic/inorganic epoxy hybrid containing nitrogen/silicon/phosphorus by sol-gel method," Thermochimica acta, vol. 453, pp. 97-104, 2007.

45. W.-L. W. Ying-Ling Liu, Keh-Ying Hsu, Wen-Hsuan Ho, "Thermal stability of epoxy-silica hybrid materials by thermogravimetric analysis," Thermochimica Acta vol. 412, pp. 139-147, 2004.

46. X. Fan, L. Lin, and P. B. Messersmith, "Surface-initiated polymerization from TiO2 nanoparticle surfaces through a biomimetic initiator: A new route toward polymer-matrix nanocomposites," Composites science and technology, vol. 66, pp. 1198-1204, 2006.

47. M. Zawrah, F. El-Kheshen, and A. Abd-Elaal, "Facile and Economic Synthesis Of Silica Nanoparticles," Journal of Ovonic Research, vol. 5, pp. 129-133, 2009.

48. R. Pruthtikul and P. Liewchirakorn, "Correlation between Siloxane Bond Formation and Oxygen Transmission Rate in TEOS Xerogel," Journal of Metals, Materials and Minerals, vol. 18, pp. 63-66, 2008.

49. Z. F. Li, M. T. Swihart, and E. Ruckenstein, "Luminescent silicon nanoparticles capped by conductive polyaniline through the self-assembly method," Langmuir, vol. 20, pp. 1963-1971, 2004. 
50. M. May, M. Asomoza, T. Lopez, and R. Gomez, "Precursor Aluminum Effect in the Synthesis of Sol- Gel Si- Al Catalysts: FTIR and NMR Characterization," Chem. Mater, vol. 9, pp. 2395-2399, 1997.

51. A. Beganskien, V. Sirutkaitis, M. Kurtinaitien, R. JuŠK Nas, and A. Kareiva, "FTIR, TEM and NMR Iinvestigations of Stöber Silica Nanoparticles," Mater Sci, vol. 10, pp. 287-290, 2004.

52. T. Otsuka and Y. Chujo, "Poly (methyl methacrylate)(PMMA)-based hybrid materials with reactive zirconium oxide nanocrystals," Polymer Journal, vol. 42, pp. 58-65, 2010.

53. S. Giri, "Synthesis and Characterization of Zirconia Coated Silica Nanoparticles for Catalytic Reactions," in National Institute Of Technology vol. Master Of Science In Chemistry Rourkela: Deemed University, 2009. 